Heike Knoll · Das System Canetti 


\section{Heike Knoll}

\section{Das System Canetti Zur Rekonstruktion eines Wirklichkeitsentwurfes}

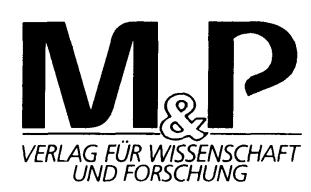


Die Deutsche Bibliothek - CIP-Einheitsaufnahme

\section{Knoll, Heike:}

Das System Canetti : zur Rekonstruktion eines

Wirklichkeitsentwurfes / Heike Knoll. - Stuttgart : M und P,

Verl. für Wiss. und Forschung, 1993

Zugl.: Frankfurt (Main), Univ., Diss., 1992

ISBN 978-3-476-45036-4

ISBN 978-3-476-45036-4

ISBN 978-3-476-04194-4 (eBook)

DOI 10.1007/978-3-476-04194-4

\section{D.30}

Dieses Werk ist einschließlich aller seiner Teile geschützt. Jede Verwertung außerhalb der engen Grenzen des Urheberrechtsgesetzes ist ohne Zustimmung des Verlages unzulässig und strafbar. Das gilt insbesondere für Vervielfältigungen, Übersetzungen, Mikroverfilmungen und Einspeicherung in elektronischen Systemen.

M \& P Verlag für Wissenschaft und Forschung ein Verlag der J. B.Metzlerschen Verlagsbuchhandlung und Carl Ernst Poeschel Verlag GmbH in Stuttgart

(c) 1993 Springer-Verlag GmbH Deutschland Ursprünglich erschienen bei J. B. Metzlersche Verlagsbuchhandlung und Carl Emst Poeschel Verlag GmbH in Stuttgart 1993 


\section{Inhaltsverzeichnis}

$\begin{array}{ll}\text { Einleitung } & 1\end{array}$

I. Die Blendung der Vernunft

1. Wider den Realismus, für einen realistischen

Roman: Canettis Forderungen an die Dichtung

2. Der Wahnsinn hat Methode:

Wirklichkeitskonstitution in der "Blendung"

3. "Ein Kopf ohne Welt":

Negative Erkenntnistheorie als Strukturprinzip

4. "Kopflose Welt":

Vom kategorischen Imperativ zur leeren

Kategorie

5. "Welt im Kopf":

Die Konsequenzen der Vernunft

64

II. Die Sprachreflexionen

1. Von der Sprachkritik zur Sprachskepsis:

Canetti und Karl Kraus

2. Sprach-Figuren:

Akustische Maske, Maskensprung und Geheimnis

3. Sprach-Bewußtsein:

Der Entwurf einer Anthropologie von der

Sprache her

4. Die Versöhnung im Wort: Sprache als konkrete Utopie 
III. Die Verwandlung

1. Mythos und Verwandlung 156

1. Der Mythos als Material 160

Exkurs:

Die Anwendung des Mythos 172

2. Die Legitimation der Dichtung

2. Verwandlung statt Vernunft:

Das Erkenntniskonzept

3. Verwandlung oder Macht:

Die Anthropologie

IV. System der Verwandlung, Poetologie des Lebens

Literaturverzeichnis 
Für Oma Gretel, die das alles

für "überflüssige Arbeit" hält. 